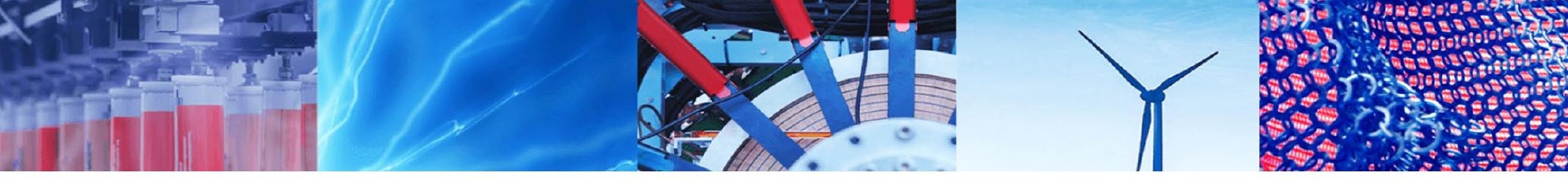

Research Article

\title{
Grid-assisted magnetron sputtering deposition of nitrogen graded TiN thin films
}

\author{
F. C. da Silva ${ }^{1,2}$ - M. A. Tunes ${ }^{3}$ - P. D. Edmondson ${ }^{4} \cdot$ N. B. Lima ${ }^{5} \cdot$ J. C. Sagás ${ }^{6} \cdot$ L. C. Fontana ${ }^{6} \cdot$ C. G. Schön ${ }^{1}$
}

Received: 30 November 2019 / Accepted: 26 March 2020 / Published online: 9 April 2020

(c) Springer Nature Switzerland AG 2020

\begin{abstract}
Titanium Nitride (TiN) films were obtained using the grid-assisted magnetron sputtering deposition technique on $\mathrm{Al}$ substrates in two conditions: under constant and variable nitrogen concentration along the thin solid film thickness. The formation of a film with variable $\mathrm{N}$ concentration (herein referred as graded film) was confirmed using energy filtered transmission electron microscopy, X-ray photoelectron spectroscopy and grazing incidence X-ray diffraction. The TiN thin films microstructures were also analysed using scanning and transmission electron microscopies (SEM and TEM). The viability of synthesizing TiN thin films with variable $\mathrm{N}$ concentration is herein proposed as an alternative method for tailoring the properties of such functional coating materials.
\end{abstract}

Keywords Titanium nitride · Electron microscopy · X-ray photoelectron microscopy · Thin solid films · Graded materials

\section{Introduction}

Durability of machining tools is largely improved by deposition of hard coatings as TiN [1-4] due to an enhanced wear resistance [5]. Nonetheless, the application of titanium nitride (TiN) thin films is not limited to machining tools. Due to its mechanical, optical and electrical properties, TiN has widespread applications in the automotive, aerospace, microelectronics and also in sanitary industries [6-15]. TiN films have been also proposed for application in nuclear reactors as coatings on nuclear fuel cladding alloys. The intention would be to increase the protection against steam oxidation in particular in the event of a severe loss-of-coolant accident $[16,17]$. A recent assessment of the radiation damage resistance of these TiN thin solid films, however, seems to preclude this application [18].
TiN thin films are quite stable stoichiometric ceramic compounds [19]. Nevertheless, the properties of such thin films can be changed via deposition and growth conditions, for example, by controlling the energy transfer to the substrate and the atomic N/Ti flux ratio which affects the structure, composition, and preferred orientation of the films [20]. The energy transfer can be changed either by heating the substrate or by applying an potential bias during deposition, resulting in the alteration of the electromagnetic field configuration within the deposition chamber. Specific N/Ti ratios of the produced film can be obtained by changing the $\mathrm{N}_{2}$-Ar plasma composition and the deposition rate [20]. The alteration of intrinsic properties like structure, crystalline orientation (texture) and residual stresses states [21] can modify functional properties of the synthesized film such as fracture toughness and adhesion [19-21].

F. C. da Silva, schoen@usp.br | ${ }^{1}$ Department of Metallurgical and Materials Engineering, Escola Politécnica da Universidade de São Paulo, São Paulo, Brazil. ${ }^{2}$ Centro Estadual de Educação Tecnológica Paula Souza (CEETEPS), FATEC/COTIA, Rua Nelson Raineri, 700 Lajeado, Cotia, SP 06702-155, Brazil. ${ }^{3}$ Chair of Non-ferrous Metallurgy, Montanuniversität Leoben, Leoben, Austria. ${ }^{4}$ Materials Science and Technology Division, Oak Ridge National Laboratory, Oak Ridge, USA. ${ }^{5}$ Instituto de Pesquisas Energéticas e Nucleares, Comissão Nacional de Energia Nuclear -SP, São Paulo, SP, Brazil. ' Laboratório de Plasmas, Filmes e Superfícies, Universidade do Estado de Santa Catarina, Joinville, Brazil. 
Functional graded materials are defined by a spatial gradient in either structure or in elemental composition which can be used for tailoring several properties of functional thin solid films [22]. In the particular case of TiN, the $\mathrm{N}$ concentration in the film can be changed during its growth by controlling the $\mathrm{N}_{2}$ supply within the deposition chamber. In principle, this may result in a compositional gradient of $\mathrm{N}$ along film thickness.

Among the variations of magnetron sputtering technique, there is the grid-assisted magnetron sputtering (GAMS), in which a grid is inserted between target and substrate [23]. The grid can be used as an additional electrode, increasing the plasma confinement [24-26] and allowing the control of substrate bombardment $[27,28]$. The grid decreases the effective gettering area, which reduces [29] and even eliminates [23] the hysteresis of process parameters, increasing the deposition stability.

The aim of the present work is to investigate the viability of synthesizing functionally graded TiN films. The mechanical characterization of both films is left as a subject of a separate work, to be published elsewhere. Therefore TiN films were deposited using the technique of gridassisted magnetron sputtering on $\mathrm{Al}$ substrates by using a variable $\mathrm{N}_{2}$ supply within the deposition chamber. These films are compared with similar films synthesized in conditions which led to a stoichiometric homogeneous TiN film. In both cases, the same bias $(-40 \mathrm{~V})$ was applied during deposition. The effect of such process parameters on the properties of the graded and homogeneous TiN thin films is analysed via modern analytical techniques.

\section{Methodology}

\subsection{Materials}

The films were deposited onto $3 \mathrm{~mm}$ thick AA1100 aluminium substrates, prepared in the geometry of a "dog-bone"type tensile sample, with dimensions represented in Fig. 1.

The use of this substrate geometry was intended to investigate the mechanical properties of the films, which will be subject of a separate publication.

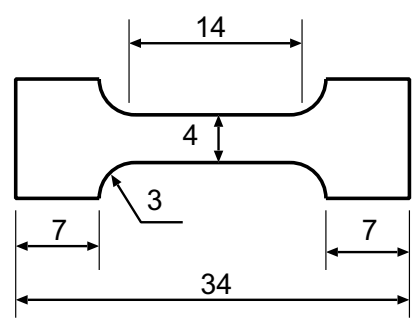

Fig. 1 Geometry of the substrates. Dimensions in $\mathrm{mm}$
The deposition surface of the substrates were prepared by grinding with $\mathrm{SiC}$ paper down to 2000 grit and subsequently polished using $1 \mu \mathrm{m}$ diamond paste in NAP cloth. In some experiments, electronic-grade Si wafer (100) substrates were also used. For the latter, the thin films were deposited under the same condition as for the Al substrates. All the substrates were ultrasonic cleaned in tetrachloroethylene for $10 \mathrm{~min}$ prior to deposition.

Grid-assisted magnetron sputtering technique was used in this work and consists of a stainless steel chamber ( $300 \mathrm{~mm}$ of diameter and $250 \mathrm{~mm}$ of height). The vacuum system is composed of mechanical and turbomolecular pumps. The magnetron (unbalanced of type II) has $100 \mathrm{~mm}$ in diameter and the grid is made of austenitic stainless steel. The copper substrate holder has $100 \mathrm{~mm}$ diameter. During deposition, the substrate temperature was monitored using a thermocouple. The argon plasma was generated by a Pinnacle Plus power supply.

Prior to deposition, the chamber was evacuated to a pressure around $10^{-2} \mathrm{~Pa}$ and the target surface was sputter-cleaned. The depositions were carried out in an atmosphere composed of a mixture of $\operatorname{Ar}(99.999 \%)$ and $\mathrm{N}_{2}(99.999 \%)$ gases. Ti sputtering target (99.5\% pure) with a thickness of $5 \mathrm{~mm}$ was used in this work. The distance between substrate and sputtering target is $60 \mathrm{~mm}$. The grid (mesh $1 \times 1 \mathrm{~mm}$ ) was kept grounded and it was placed $20 \mathrm{~mm}$ from the target. In all depositions, the total pressure was kept at around of $0.40 \mathrm{~Pa}$, monitored with a capacitive gauge, whilst the substrates were heated at $573 \mathrm{~K}$ by a set of halogen lamps placed behind the substrate holder. The temperature was controlled by a type $\mathrm{K}$ thermocouple inserted in the substrate holder. The flow rates of the gases were monitored using mass flow controllers (20 sccm full scale). The depositions were performed in constant current mode $(2.00 \mathrm{~A})$, which resulted in a target power density around $13 \mathrm{~W} / \mathrm{cm}^{2}$. For each film, a Ti interlayer with thickness of $\approx 150 \mathrm{~nm}$ was deposited before the $\mathrm{TiN}_{x}$ films deposition, in order to improve film adhesion as previously reported in literature [30-33]. The total deposition time was fixed at $30 \mathrm{~min}$. Figure 2 shows a schematic representation of the experimental setup used in this work for the synthesis of TiN thin solid films and further details can be found elsewhere [23].

In order to achieve $\mathrm{N}$ content differences in the film, two conditions of $\mathrm{N}_{2}$ flow rate were used: constant (homogeneous film) and variable (graded film). To determine the required $\mathrm{N}_{2}$ flow rate, the hysteresis curve for the system was obtained before deposition. For the homogeneous films, the $\mathrm{N}_{2}$ flow rate was fixed at approximately $8.0 \mathrm{sccm}$, close to the first critical point, but avoiding target poisoning [34]. For the graded film, the $\mathrm{N}_{2}$ flow rate was set initially to $1.5 \mathrm{sccm}$ and after that it was increased in steps of $0.4 \mathrm{sccm} \mathrm{min} \mathrm{m}^{-1}$ up to around 
Fig. 2 Experimental setup for the grid-assisted magnetron sputtering technique used in this work

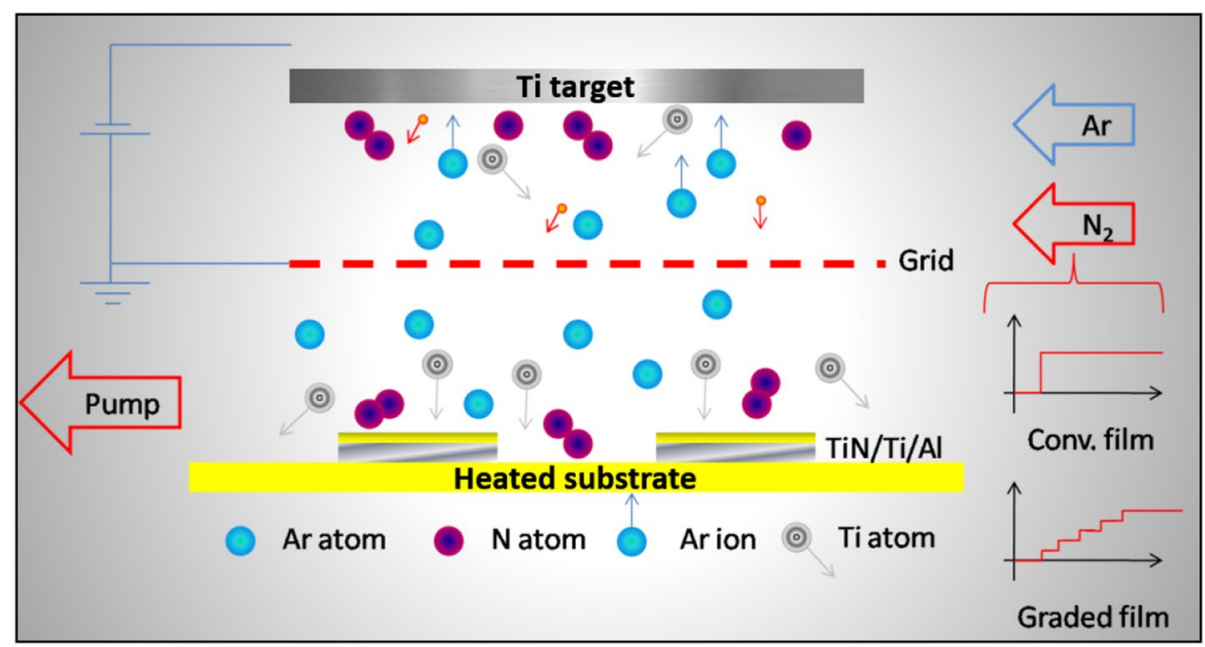

of $8.0 \mathrm{sccm}$. Then, the $\mathrm{N}_{2}$ flow rate was maintained constant during the last $15 \mathrm{~min}$ of deposition. For both cases (homogeneous and graded films), the DC substrate bias condition was set to $-40 \mathrm{~V}$. Deposition rate was about $65 \mathrm{~nm} \mathrm{~min}^{-1}$ for the two $\mathrm{N}_{2}$ flow conditions, once that all depositions were performed in metallic mode. Substrate ion current density was around $0.13 \mathrm{~mA} \mathrm{~cm}^{-2}$ for all conditions. Such low value is typical for GAMS due to the plasma confinement between the grid and the target. In these conditions, the energy delivery into growing films by bombarding ions (ratio between the substrate power density and deposition rate) [35] is estimated in $4.8 \times 10^{4} \mathrm{~J} \mathrm{~cm}^{-3}$

\subsection{Film characterization}

The microstructure of the films was investigated using Scanning Electron Microscopy (SEM) in a FEI F50 SEM equipped with field emission gun. The films were also analyzed using Transmission Electron Microscopy (TEM) either using a Hitachi H-9500 TEM operating at $300 \mathrm{keV}$ with $\mathrm{a} \mathrm{LaB}_{6}$ filament for the homogeneous film or a JEOL JEM $2100 \mathrm{~F}$ microscope at $200 \mathrm{keV}$ operating a Schottky Field Emission Gun for the graded film. A Gatan Image Filter (GIF) Quantum SE was also used for Energy Filtered TEM (EFTEM) analysis for both films.

$X$-ray diffraction was performed in the Grazing Incidence mode (GIXRD) using a Rigaku Multiflex diffractometer in the $\theta-2 \theta$ configuration, using a scanning range of $25^{\circ} \leq 2 \theta \leq 80^{\circ}$, with a step of $0.02^{\circ}$ and $6 \mathrm{~s}$ acquisition time per step. Cu K $\alpha$ characteristic X-ray line $(\lambda=0.15406 \mathrm{~nm})$ was used in these experiments. The grazing incidence X-ray diffraction (GIXRD) experiments were performed using incidence angles of $15^{\circ}$.

\subsubsection{X-ray photoelectron spectroscopy}

In order to confirm the $\mathrm{N}$ gradient in the films deposited under variable $\mathrm{N}_{2}$ flow rate and compare with the EFTEM measurements, X-ray photoelectron (XPS) spectra of samples deposited onto Si (100) under - $40 \mathrm{~V}$ bias were obtained. The measurements were carried out in a ThermoScientific K-Alpha system. Homogeneous and graded films were sputter cleaned using an Ar ion gun with energy of $2 \mathrm{keV}$ during $240 \mathrm{~s}$ in an area of $2.00 \mathrm{~mm}^{2}$ to remove surface contamination, monitored by observing the signals of $\mathrm{O}$ and $\mathrm{C}$. Before and after this cleaning, a survey spectra ( 0.00 to $1350.00 \mathrm{eV}$ ) was obtained to verify the composition of the films. For these measurements, an energy step of $0.500 \mathrm{eV}$, pass energy of $200.00 \mathrm{eV}$ and dwell time of 10 ms were used with a X-ray spot of $400 \mu \mathrm{m}$. The spectra are an average of three scans. For both samples only Ti and $N$ were detected after the surface cleaning. The Ti $2 p$ and $\mathrm{N}$ $1 \mathrm{~s}$ photo-peaks were also measured with energy step of $0.025 \mathrm{eV}$, pass energy of $20.00 \mathrm{eV}$, dwell time de $100 \mathrm{~ms}$, using the same X-ray spot. Each spectra is an average of ten scans.

To measure the compositional gradient along film thickness for graded film, depth profile measurements were performed using the same acquisition parameters for survey, Ti $2 p$ and N 1 s spectra, but using a X-ray spot of $30 \mu \mathrm{m}$. The etching was made using the same Ar ion gun.

\section{Results and discussion}

The microstructures of homogeneous and graded films deposited onto Si (100) substrate at $-40 \mathrm{~V}$ bias are shown in Fig. 3. The fracture characteristics for both films show a columnar structure in the mesoscopic 
(a)

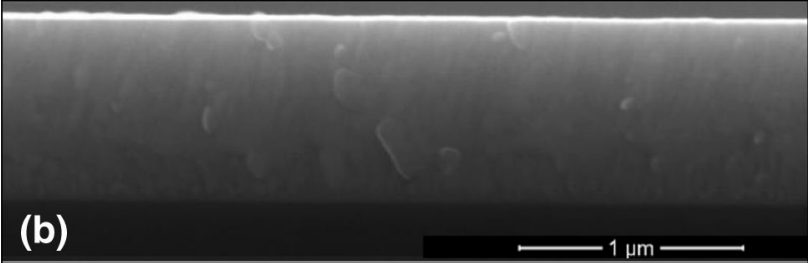

Fig. 3 Scanning electron microscopy micrographs of TiN thin films deposited on Si substrates, corresponding to the $-40 \mathrm{~V}$ bias condition showing: $\mathbf{a}$ homogeneous and $\mathbf{b}$ graded films

scale. The deposition rate of both films was estimated as $65 \mathrm{~nm} \mathrm{~min}{ }^{-1}$, but it is observed that the thickness of the graded film is slightly larger than the thickness of the homogeneous film. This can be attributed to a slightly higher deposition rate while the $\mathrm{N}_{2}$ flow rate is increasing during deposition. The compound (TiN) sputtering yield is lower than that for metal (Ti). So, once that the compound formation on target surface is lower for small $\mathrm{N}_{2}$ flow rate [34], a higher net deposition rate is obtained in graded films when compared to homogeneous one.

A microstructural characterization of both films with TEM is shown in Fig. 4. It is observed that compact films are obtained in both $\mathrm{N}_{2}$ flow conditions. The main difference consists that the columnar aspect of the graded film, which was observed in the mesoscale and it also manifests in the nanoscale. The diffraction pattern (DP) insets in Fig. 4a, b show that such TiN thin films have grain sizes in the nanoscale.

A degree of preferred orientation is expected in the sputtering deposition process, due to the directionality of material growth, but this does not necessarily means a directional growth as a micro-mechanism. The variable influx of nitrogen introduces a new gradient in the process, changing the microscopic growth mechanism. The grain sizes normal to the film plane, however, are similar in both cases and correspond to about $50 \mathrm{~nm}$.

Figure 5 shows the EFTEM images obtained for the graded film. The image is obtained selecting the energy loss peaks attributed to $\mathrm{N}, \mathrm{Ti}$ and $\mathrm{Al}$, allowing to investigate the distribution of these elements. The results confirm the $\mathrm{N}$ gradient in the graded film. This is not observed in the film deposited under constant $\mathrm{N}_{2}$ flow, Fig. 6 which shows a homogeneous distribution of nitrogen along film thickness.

The formation of a columnar structure in deposited films is usually assumed to be deleterious for the fracture toughness [35-37]. This is due to the formation of voids in the grain boundaries, leading to a preferred path for cracking perpendicular to the film surface. In the present result, presumably due to the use of the GAMS technique, the films were observed to be compact and no void could be observed. Therefore this cracking mechanism is not expected to operate in the present films.

A higher $\mathrm{N}$ concentration is observed at the interface of the graded and homogeneous films. Two hypothesis can be formulated: (1) a spike in $\mathrm{N}_{2}$ flow rate when the the
Fig. 4 Microstructure characteristic of the obtained films ( $-40 \mathrm{~V}$ bias). Transmission Electron Microscopy images obtained in a, c bright field and b, $\mathbf{d}$ dark field (the corresponding reflections are indicated in the insets of figures $\mathbf{a}$ and $\mathbf{c}$ of the $\mathbf{a}, \mathbf{b}$ homogeneous and $\mathbf{c}, \mathbf{d}$ graded films

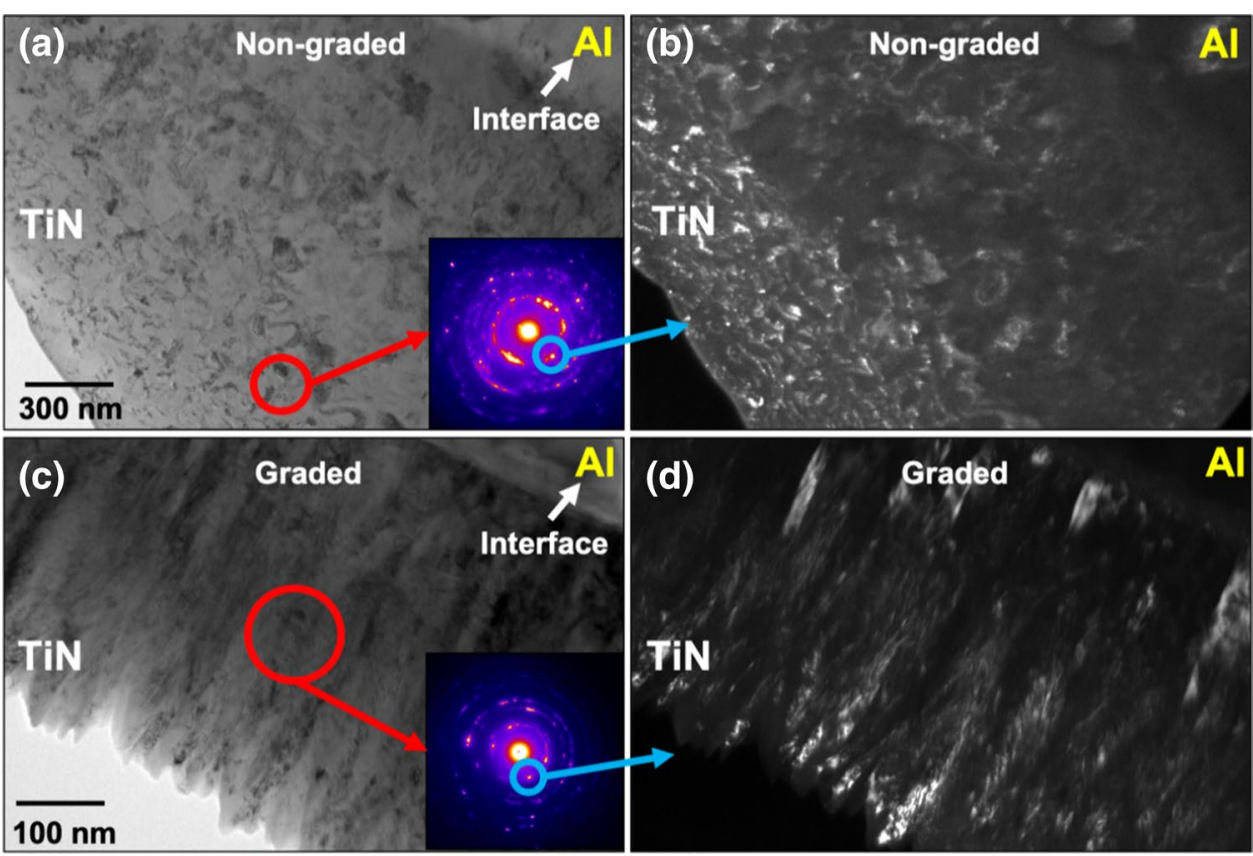




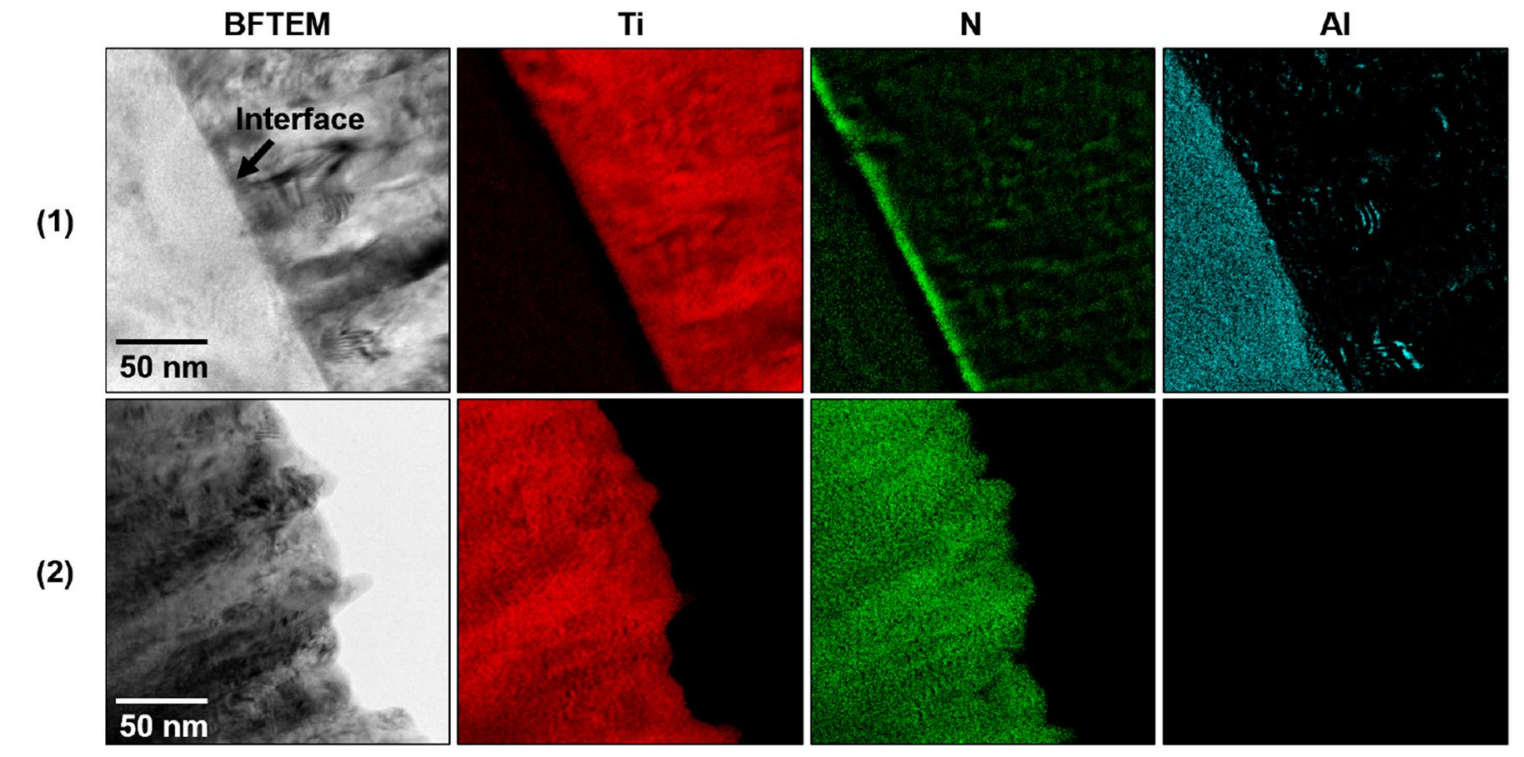

Fig. 5 Elemental distributions in the graded film ( $-40 \mathrm{~V}$ bias) using EFTEM: (1) - region close to the interface with the substrate and (2) region close to the surface of the film

Fig. 6 Elemental distributions in the constant film $(-40 \mathrm{~V}$ bias) using EFTEM: (1) -region close to the surface of the film and (2)-region close to the interface with the substrate [38]

(1)

(2)

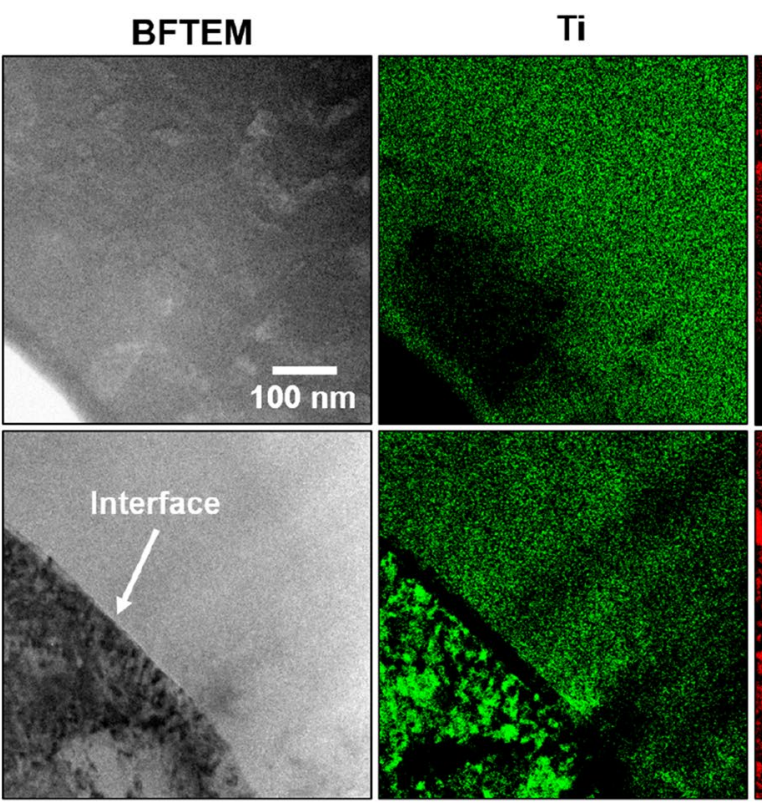

$\mathbf{N}$

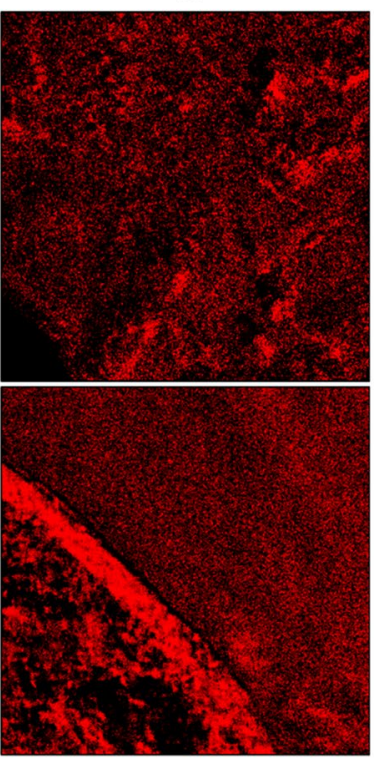

mass flow controller is switched on, leading to an excess of $\mathrm{N}$ in the working gas or (2) a $\mathrm{N}$ diffusion in the TiN layer. The second hypothesis is related to the $\mathrm{N}$ incorporation in low $\mathrm{N}$ partial pressures which is accommodated as defects in the structure of the compound. These defects (probably $\mathrm{N}$ vacancies in the interstitial sublattice) allow diffusion to take place easier within the graded film. The film grown under constant $\mathrm{N}_{2}$ flow conditions forms close to the optimal stoichiometry, producing a non-defective lattice, hence diffusion is suppressed in this film. The concentration of nitrogen at the interface is a consequence of the extremely low nitrogen activity in $\mathrm{Al}$, thus creating a steep chemical potential gradient at the interface leading to attraction of $\mathrm{N}$.

To quantify the nitrogen gradient along the film thickness, the $\mathrm{N} / \mathrm{Ti}$ atomic ratio was determined as a function of etching time during $\mathrm{X}$-ray photoelectron spectroscopy (XPS) depth profile measurements (Fig. 7a). It must be pointed out that due to preferential sputtering effects the N/Ti ratio can be underestimated. Nevertheless, a gradient is indeed observed. Close to the surface, the ratio remains stable and near 0.95 (same value obtained for 


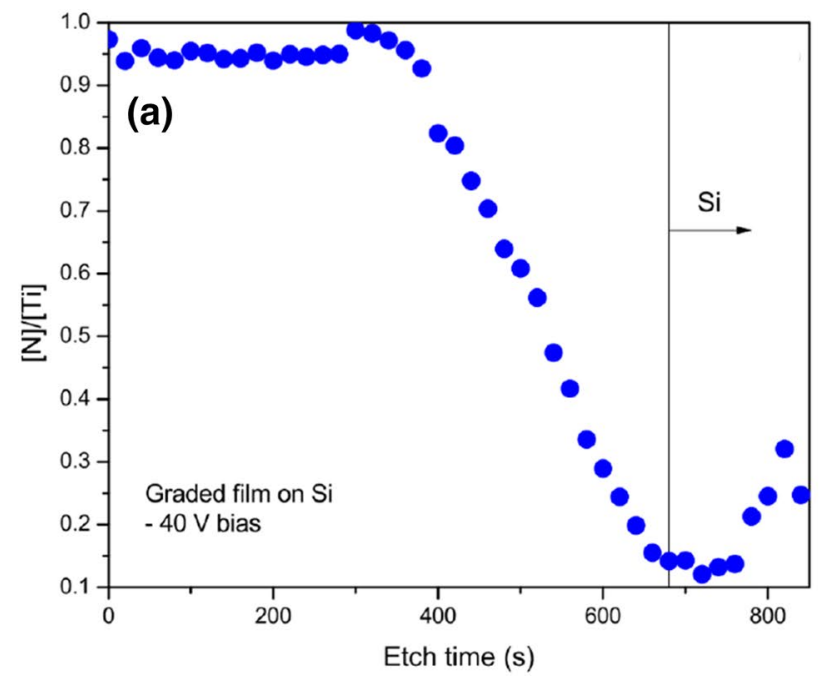

Fig. 7 a Gradient of N/Ti ratio as a function of etching time measured with XPS. Film deposited onto silicion under $-40 \mathrm{~V}$ bias and $\mathbf{b}$ Ti $2 p$ XPS photopeak for different etching times. At $20 \mathrm{~s}$, the spec-

homogeneous film). After 350 s of etching, the ratio starts to decrease until reaches a minimum value near 0.10 . After the Si signal from substrate appears, a small increase in N/ Ti ratio is observed, which can be related to the $\mathrm{N}$ accumulation observed in the EFTEM results.

A clear transition of Ti $2 p$ spectra is noticed when lowering $\mathrm{N} / \mathrm{Ti}$ ratio (Fig. $7 \mathrm{~b}$ ). Close to the surface, the typical spectrum of TiN is observed, including the satellites peaks. Increasing etching time (and depth), the spectrum is shifted to lower binding energies, changing to a near pure $\mathrm{Ti}$ spectrum. It indicates that for low $\mathrm{N} / \mathrm{Ti}$ ratio (below 0.3 ), the $\mathrm{N}$ is in solid solution with $\mathrm{Ti}$ [39].

The results of the film characterization as reported, demonstrates that the variable influx of $\mathrm{N}_{2}$ allows the generation of a concentration gradient in the film, which likely introduces a gradient of mechanical properties in the normal direction of the film plane.

\subsection{GIXRD tests}

Figure 8 and shows the GIXRD patterns of the TiN coatings deposited onto Al substrates with constant (Fig. 8a) and graded $\mathrm{N}_{2}$ (Fig. 8b) flow. The results confirm that the deposited film consists of stoichiometric TiN. The lattice parameter of the film produced under constant $\mathrm{N}_{2}$ flow condition is $a_{0}=0.4267 \pm 0.0003 \mathrm{~nm}$. The reported lattice parameter is the average values obtained for the (111) and (200) diffraction peaks. For the graded $\mathrm{N}_{2}$ flow, the results exhibit broader peaks compared to the constant cases, suggesting that the lattice parameter is varying in the sample, this is expected due to the nitrogen gradient which was identified before. Therefore no reliable determination of lattice

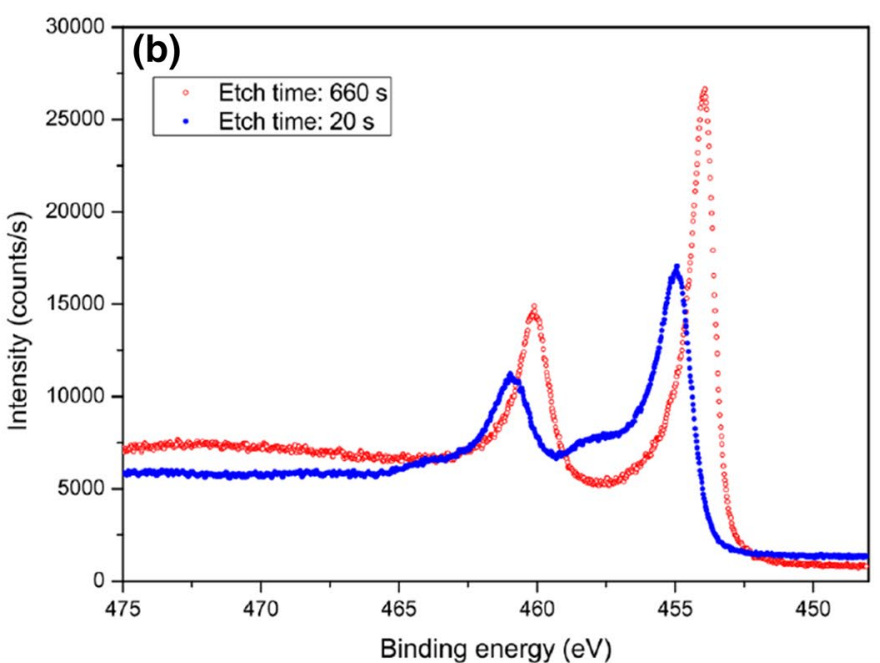

trum is typical of stoichiometric TiN, while during $660 \mathrm{~s}$ of etching, the spectrum resembles metallic $\mathrm{Ti}$
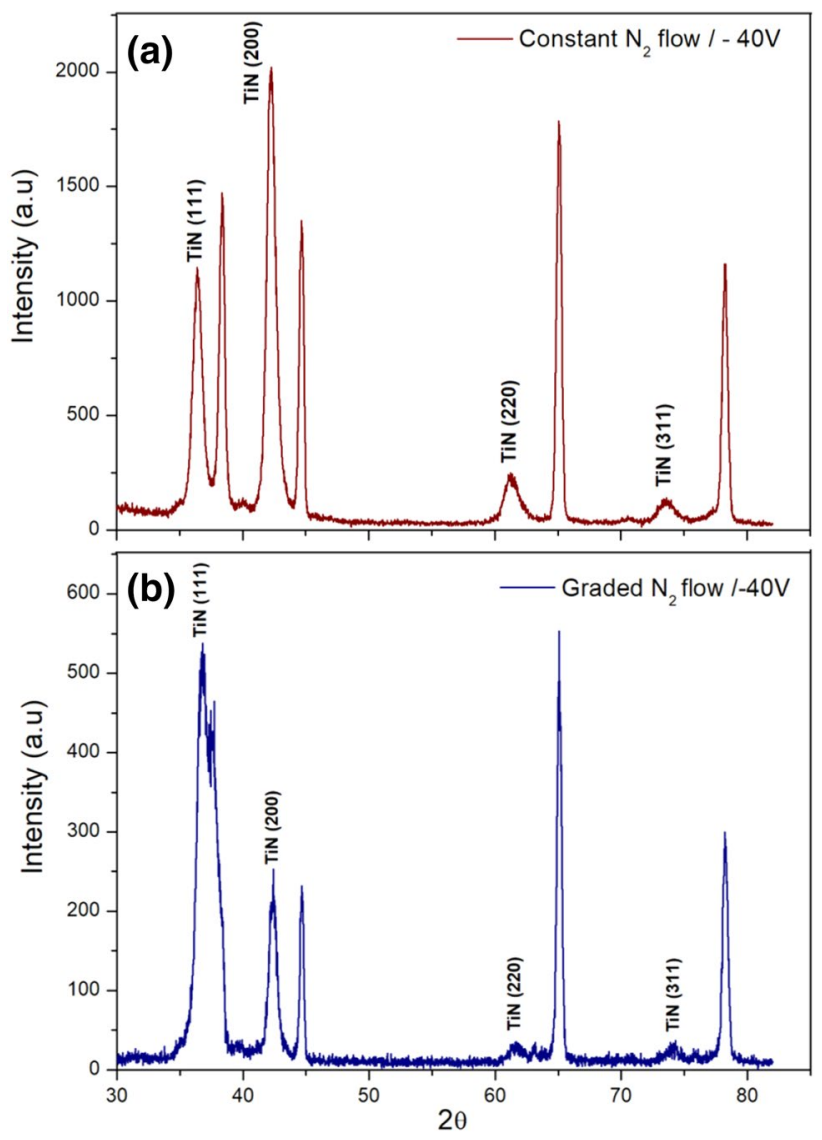

Fig. 8 GIXRD diffraction pattern for the a homogeneous and $\mathbf{b}$ graded film 
parameter is possible. The variation of $\mathrm{N}_{2}$ flow along thickness appears change the preferred orientation of the film, since the intensity of the (200) peak is the largest in the constant case, while peak (111) is the more intense in the graded film, agreeing with [20].

\section{Conclusions}

In the present work the deposition of functionally graded TiN films onto aluminum substrates via grid-assisted magnetron sputtering were investigated. The films were grown in two nitrogen supply conditions: with constant supply (corresponding to the stoichiometric TiN compound) and by increasing the supply during deposition, leading to $\mathrm{N}$ graded films, as confirmed by EFTEM and XPS measurements. The production of functionally graded TiN films is, therefore, possible.

Acknowledgements The present work was supported by the Brazilian National Research, Technology and Innovation Council (CNPq) under Contract Number 312424/2013-2 and by the São Paulo State Research Funding Foundation (FAPESP) under Contract Number 2016/05768-2. This project was also partially supported by the Santa Catarina State Research Funding Agency (FAPESC) through the program PAP in association with the Santa Catarina State University under Contract Number PAP-TR-655. MAT was supported through the ASTRO fellowship, a United States Department of Energy workforce development program implemented at Oak Ridge National Laboratory through the Oak Ridge Institute for Science and Education under Contract DE-AC05-06OR23100.

\section{Compliance with ethical standards}

Conflict of interest The authors declare no conflict of interest

\section{References}

1. Gerth J, Wiklund U (2008) The influence of metallic interlayers on the adhesion of PVD TiN coatings on high-speed steel. Wear 264:885-892

2. Kovalchuk AV, Kontantinov SV, Tkachenko HA, Komarov FF, Kntantinov VM (2016) The effect of steel substrate pre-hardening on structural, mechanical and tribological properties of magnetron sputtered TiN and TiAIN coatings. Wear 352-353:92-101

3. Lim CYH, Lim SC, Lee KS (1999) The performance of TiN-coated high speed steel tool inserts in turning. Tribol Int 32:393-398

4. Qiu M, Zhang YZ, Shangguan B, Du SM, Yan ZW (2007) The relationships between tribological behavior and heat-transfer capability of Ti6AI4V alloys. Wear 263:653-657

5. Ohring $M(2002)$ The materials science of thin films. Academic Press, Hoboken

6. Ponon NK, Appleby DJR, Arac E, King PJ, Ganti S, Kwa KSK, O'Neill A (2015) Effect of deposition conditions and post-deposition anneal on reactivelly sputtered titanium nitride thin films. Thin Solid Films 578:31-37

7. Zhao G, Zhang T, Zhang T, Wang J, Han G (2008) Electrical and optical properties of titanium nitride coatings prepared by atmospheric pressure chemical vapor deposition. J Non-cryst Solids 354:1272-1275

8. Elmkhah M, Attarzadeh F, Fattah-Al Hosseini A, Kim KH (2018) Microstructure and electrochemical comparisson between TiN coatings deposited through HIPIMS and DCMS techniques. J Alloys Compd 735:422-429

9. Arnell RD, Colligon JS, Minnebaev KF, Yurasova VE (1996) The effect of nitrogen content on the structural and mechanical properties of TiN films produced by sputtering. Vacuum 47:425-431

10. Zhang S, Zhu W (1993) TiN coating of tool steels: a review. J Mater Process Technol 39:165-177

11. Kainz C, Schalk N, Tkadletz M, Mitterer C, Czettl C (2019) The effect of $b$ and $c$ addition on microstructure and mechanical properties of tin hard coatings grown by chemical vapor deposition. Thin Solid Films 688:137283

12. Kainz C, Schalk N, Tkadletz M, Mitterer C, Czettl C (2019) Microstructure and mechanical properties of CVD TiN/TiBN multilayer coatings. Surf Coat Technol 370:311-319

13. Saringer C, Franz R, Zorn K, Mitterer C (2016) Effect of discharge power on target poisoning and coating properties in reactive magnetron sputter deposition of tin. J Vac Sci Technol A Vac Surf Films 34(4):041517

14. Weirather T, Chladil K, Sartory B, Caliskanoglu D, Cremer R, Kölker W, Mitterer C (2014) Increased thermal stability of $\mathrm{Ti}_{1-x} \mathrm{Al}_{x} \mathrm{~N} / \mathrm{TiN}$ multilayer coatings through high temperature sputter deposition on powder-metallurgical high-speed steels. Surf Coat Technol 257:48-57

15. Arif $M$, Sauer $M$, Foelske-Schmitz A, Eisenmenger-Sittner $C$ (2017) Characterization of aluminum and titanium nitride films prepared by reactive sputtering under different poisoning conditions of target. J Vac Sci Technol A Vac Surf Films 35(6):061507

16. Alat E, Motta AT, Comstock RJ, Partezana JM, Wolfe DE (2015) Ceramic coating for corrosion (c3) resistance of nuclear fuel cladding. Surf Coat Technol 281:133-143

17. Alat E, Motta AT, Comstock RJ, Partezana JM, Wolfe DE (2016) Multilayer (TiN, TiAIN) ceramic coatings for nuclear fuel cladding. J Nucl Mater 478:236-244

18. Tunes MA, Silva FC, Camara O, Schön CG, Segás JC, Fontana LC, Donnelly SE, Greaves G, Edmondson PD (2018) Energetic particle irradiation study of tin coatings: are these films appropriate for accident tolerant fuels? J Nucl Mater 512:239-245

19. Hultman $L$ (2000) Thermal stability of nitride thin films. Vacuum 57(1):1-30

20. Mahieu S, Depla D (2009) Reactive sputter deposition of TiN layers: modelling the growth by characterization of particle fluxes towards the substrate. J Phys D Appl Phys 42(5):053002

21. Abadias G, Chason E, Keckes J, Sebastiani M, Thompson GB, Barthel E, Doll GL, Murray CE, Stoessel CH, Martinu L (2018) Review article: stress in thin films and coatings: current status, challenges, and prospects. J Vac Sci Technol A 36(2):020801

22. Naebe M, Shirvanimoghaddam K (2016) Functionally graded materials: a review of fabrication and properties. Appl Mater Today 5:223-245

23. Fontana LC, Muzart JLR (1999) Triode magnetron sputtering TiN film deposition. Surf Coat Technol 114:7-12

24. Sagás JC, Fontana LC, Maciel HS (2011) Influence of electromagnetic confinement on the characteristics of a triode magnetron sputtering system. Vacuum 85:705-710

25. Sagás JC, Duarte DA, Fissmer SF (2011) Effect of oxygen concentration and system geometry on the current-voltage relations during reactive sputter deposition of titanium dioxide thin films. Vacuum 85:1042-1045

26. Sagás JC, Pessoa RS, Maciel HS (2018) Langmuir probe measurements in a grid-assisted magnetron sputtering system. Braz J Phys 48:61-66 
27. Duarte DA, Sagás JC, Fontana LC, Silva Sobrinho AS, Cinelli MJ (2010) Control of the substrate temperature using a triode magnetron sputtering system. Eur Phys J Appl Phys 52:31001

28. Sagás JC, Duarte DA, Fontana LC (2012) Unusual behaviour of current-voltage relations in an unbalanced grid-assisted magnetron sputtering system. J Phys D Appl Phys 45:505204

29. Sagás JC, Duarte DA, Irala DR, Fontana LC, Rosa TR (2011) Modeling reactive sputter deposition of titanium nitride in a triode magnetron sputtering system. Surf Coat Technol 206:1765-1770

30. Van Stappen M, Malliet B, De Schepper L, Stals LM, Celis JP, Roos JR (1989) Influence, of Ti intermediate layer on properties of tin coatings deposited on various substrates. Surf Eng 5(4):305-310

31. De Schepper L, D'Olieslaeger M, Knuyt G, Stals LM, Van Stappen M, Malliet B, Celis JP, Roos JR (1989) Initial growth and epitaxy of PVD TiN layers on austenitic steel. Thin Solid Films 173(2):199-208

32. Quaeyhaegens C, Stals LM, Van Stappen M, De Schepper L (1991) Interface study of TiN- and Ti-TiN- coated stainless steel AISI 304 with asymmetric glancing angle $\mathrm{X}$-ray diffraction and classical Bragg-Brentano X-ray diffraction. Thin Solid Films 197:37-46

33. Gómes AG, Recco AAC, Lima NB, Martinez LG, Tschiptschin AP, Souza RM (2010) Residual stresses in titanium nitride thin films obtained with step variation of substrate bias voltage during deposition. Surf Coat Technol 204:3228-3233
34. Strijckmans K, Schelfhout R, Depla D (2018) Tutorial: hysteresis during the reactive magnetron sputtering process. J Appl Phys 124(24):241101

35. Musil J (2012) Hard nanocomposite coatings: thermal stability, oxidation resistance and toughness. Surf Coat Technol 207:50-65

36. Musil J (2015) Flexible hard nanocomposite coatings. RCS Adv 5:60482-60495

37. Musil J (2017) Flexible antibacterial coatings. Molecules 22:813

38. da Silva FC, Tunes MA, Sagás JC, Schön CG (2018) Influence of substrate stiffness and of PVD parameters on the microstructure and tension fracture characteristics of TiN thin films. Procedia Struct Integr 13:658-663

39. Kuznetsov MV, Zhuravlev MV, Shalayeva EV, Gubanov VA (1992) Influence of the deposition parameters on the composition, structure and X-ray photoelectron spectroscopy spectra of Ti-N films. Thin Solid Films 215:1-7

Publisher's Note Springer Nature remains neutral with regard to jurisdictional claims in published maps and institutional affiliations. 